\title{
Skp-cullin-F box E3 ligase component FBXL2 ubiquitinates Aurora B to inhibit tumorigenesis
}

\author{
BB Chen ${ }^{*, 1,2}$, JR Glasser ${ }^{1}$, TA Coon ${ }^{1}$ and RK Mallampalli*, ${ }^{*, 1,4}$
}

\begin{abstract}
Aurora B kinase is an integral regulator of cytokinesis, as it stabilizes the intercellular canal within the midbody to ensure proper chromosomal segregation during cell division. Here we identified that the ubiquitin E3 ligase complex SCF ${ }^{\mathrm{FBX} 2}$ mediates Aurora $B$ ubiquitination and degradation within the midbody, which is sufficient to induce mitotic arrest and apoptosis. Three molecular acceptor sites $\left(\mathrm{K}^{102}, \mathrm{~K}^{103}\right.$ and $\left.\mathrm{K}^{207}\right)$ within Aurora $\mathrm{B}$ protein were identified as important sites for its ubiquitination. A triple Lys mutant of Aurora B $\left(\mathrm{K}^{102} /^{103} / 2^{207 \mathrm{R}}\right)$ exhibited optimal resistance to $\mathrm{SCF}^{\mathrm{FBX} 2}$-directed polyubiquitination, and overexpression of this variant resulted in a significant delay in anaphase onset, resulting in apoptosis. A unique small molecule F-box/LRR-repeat protein 2 (FBXL2) activator, BC-1258, stabilized and increased levels of FBXL2 protein that promoted Aurora B degradation, resulting in tetraploidy, mitotic arrest and apoptosis of tumorigenic cells, and profoundly inhibiting tumor formation in athymic nude mice. These findings uncover a new proteolytic mechanism targeting a key regulator of cell replication that may serve as a basis for chemotherapeutic intervention in neoplasia.
\end{abstract}

Cell Death and Disease (2013) 4, e759; doi:10.1038/cddis.2013.271; published online 8 August 2013

Subject Category: Cancer

Normally, mammalian cells deploy numerous checkpoint enzymes that ensure faithful cell cycle progression and mitosis. However, if one or more of these checkpoint enzymes are dysregulated, it can result in uncontrolled cell growth and division, eventually leading to neoplastic growth. One of these dysregulated checkpoint proteins is Aurora B; in cancerous cells, Aurora $B$ is highly overexpressed, causing abnormal distribution of DNA, which is highly linked to maligancy. ${ }^{1,2}$ Aurora B kinase is a multi-role protein that localizes within different intracellular organelles, targeting many substrates to regulate different mitotic events. Aurora B has been shown to localize on mitotic chromosomes, specifically associating with kinetochores in metaphase, but dislocates at anaphase and later accumulates on the midzone and midbody. ${ }^{3-5}$ Aurora $B$ has been shown to have important roles in chromosome biorientation, ${ }^{6}$ chromosome condensation and cohesion, ${ }^{7}$ cytokinesis $^{8}$ and the spindle assembly checkpoint. ${ }^{9}$ Mammalian cells are extremely sensitive to Aurora B modulation, as chemical inhibition, siRNA knockdown of Aurora B or overexpression of the kinase-dead form of Aurora B, all lead to similar phenotypes, including chromosome misalignment and cytokinesis failure. ${ }^{10-13}$ Aurora B protein is subject to extensive posttranslational modification throughout the cell cycle. For example, the anaphase-promoting complex through binding to the degradation-targeting proteins Cdh1 and Cdc20, or assembly of an E3 ligase complex comprising Cullin3 with the Bric-a-brac-Tramtrack-Broad complex Kelch proteins (KLHL21) is sufficient to ubiquitinate Aurora $B .^{3,13,14}$ Hence, posttranslational events within Aurora B protein might be important in governing kinase relocation or levels during early phases of the mitotic program, and yet other effectors might regulate local concentrations of Aurora B within the midbody during telophase as feedback inhibitory or activating signals.

The Skp-Cullin-F box (SCF) ubiquitin E3 ligase machinery regulates cell cycle progression, centrosome stability and mitotic fidelity. ${ }^{15-19}$ The SCF complex contains a catalytic core consisting of Skp1, Cullin1 and the E2 ubiquitinconjugating (Ubc) enzyme, and a F-box component that acts as a receptor, targeting numerous substrates via phosphodegron-elicited interactions. ${ }^{20-23}$ There have been limited studies on SCF complex functions during mitosis; however, recently it was demonstrated that the $\mathrm{SCF}^{\text {cyclinF }}$ complex controls centrosome homeostasis and mitotic fidelity through CP110 degradation. ${ }^{19}$ These SCF-based studies focused on centrosome regulation, and thus far their limited data, demonstrating the ability of an F-box protein to target midbody proteins. However, the observation that Skp1 interacts with centromere-associated protein $\mathrm{E}$ at the midbody suggests that SCF-based ligase complexes might regulate

\footnotetext{
${ }^{1}$ Department of Medicine, Pulmonary, Allergy and Critical Care Medicine, UPMC Montefiore, University of Pittsburgh, Pittsburgh, PA, USA; ${ }^{2}$ Department of Acute Lung Injury Center of Excellence, University of Pittsburgh, Pittsburgh, PA, USA; ${ }^{3}$ Department of Cell Biology and Physiology, University of Pittsburgh, Pittsburgh, PA, USA and ${ }^{4}$ Medical Specialty Service Line, Veterans Affairs Pittsburgh Healthcare System, Pittsburgh, PA, USA

*Corresponding author: BB Chen or RK Mallampalli, Department of Medicine, Pulmonary, Allergy and Critical Care Medicine, UPMC Montefiore, University of Pittsburgh, 3459 Fifth Avenue, NW 628, Pittsburgh, PA 15213, USA. Tel: 412692 2112; Fax: 412692 2260; E-mail: chenb @ upmc.edu

Keywords: ubiquitin; tumor; proteolysis; drug; small molecule

Abbreviations: A549, adenocarcinomic human alveolar basal epithelial cell; BrdU, bromodeoxyuridine (5-bromo-2'-deoxyuridine; BARD1, BRCA1-associated RING domain 1; KLHL21, Bric-a-brac-Tramtrack-Broad complex Kelch proteins; CCT, cytidylyltransferase; Cdk11, cyclin-dependent kinase 11; FBXO3, F-box-only protein 3; FACS, fluorescence-activated cell sorting; FBXL2, F-box/LRR-repeat protein 2; K562, human erythroleukemic cell line; MLE, murine lung epithelial; PLk4, polo-like kinase 4; SCF, Skp-Cullin-F box; THP1, human acute monocytic leukemia cell line; U937, human leukemic monocyte lymphoma cell line; WT, wild type Received 07.5.13; revised 10.6.13; accepted 19.6.13; Edited by M Agostini
} 
cytokinesis-associated proteins. ${ }^{24}$ Recently, we demonstrated that the SCF subunit, F-box/LRR-repeat protein 2 (FBXL2), targets Aurora B for its ubiquitination to mediate its disposal in cells, an effect antagonized by the calcium sensor, calmodulin. ${ }^{25}$ However, given the importance of Aurora $B$ in cell cycle progression, understanding the molecular mechanism whereby FBXL2 targets Aurora B provides an opportunity for devising strategies directed at generating potent SCF ${ }^{\mathrm{FBXL2}}$ agonists that might impact neoplastic growth.

Here our data suggest that FBXL2 acts as a functional inhibitor with regard to cell cycle progression, specifically within mitosis. FBXL2 localizes at the midbody during cytokinesis and exhibits tumor-suppresser activity by site-specific ubiquitination and degradation of Aurora B in human lung cancer cell lines and leukemic cells. Further, we developed a small molecule, BC-1258, which is sufficient to stabilize and upregulate FBXL2 levels, and, when administered in vivo, prematurely depletes Aurora B by $\mathrm{SCF}^{\mathrm{FBXL} 2}$-induced ubiquitination and degradation, leading to cell death, and inhibiting growth of human leukemic cells in a xenograft model. This study provides a new strategy for degrading Aurora B protein as a potential means to modulate tumorogenesis.

\section{Results}

FBXL2 selectively induces Aurora B degradation. We first tested over $30 \mathrm{~F}$-box proteins that might be involved in Aurora $B$ degradation. Twenty-seven randomly selected F-box plasmids ( $F B X L, F B X W$ and $F B X O$ family members) were expressed in a transformed murine lung epithelial (MLE) cell line (Figures 1a-c). Twenty-four hours later, cells were collected and cell lysates were analyzed for the expression of immunoreactive F-box protein and Aurora B protein. Only the FBXL2 plasmid expression decreased Aurora $B$ protein mass. Next, cells were transfected with increasing amounts of $F B X L 2$ plasmid (Figure 1d). Aurora $B$ was degraded in a dose-dependent manner. Ectopic FBXL2 plasmid expression significantly decreased the half-life $\left(t_{1 / 2}\right)$ of Aurora B, whereas FBXL2 knockdown markedly increased Aurora B's lifespan (Figure 1e). We further tested FBXL2 in other cell lines; ectopic expression of FBXL2 plasmid also resulted in a reduction in endogenous Aurora $B$ levels in adenocarcinomic human alveolar basal epithelial cell (A549), human embryonic kidney 293 and B-lymphocyte cell lines (Supplementary Figure S1A). To assess the specificity of FBXL2 substrate targeting, we tested another related kinase family member, Aurora $A$, as we previously identified that Aurora $A$ is a substrate of FBXL7. ${ }^{26}$ Expression of $F B X L 2$ plasmid did not decrease Aurora $A$ protein levels or its $t_{1 / 2}$ (Supplementary Figures S1B and C). Moreover, a random F-box plasmid (FBXL16) from the FBXL family was also selected and ectopically expressed in cells demonstrating the lack of ability of this protein to disrupt Aurora B stability (Supplementary Figure S1D). Consistent with a posttranslational effect, FBXL2 plasmid overexpression did not significantly alter Aurora B steady-state mRNA levels (data not shown).
FBXL2 depletes Aurora B within the midbody during mitosis. Costaining of synchronized MLE cells with FBXL2 and Aurora B antibodies demonstrated that FBXL2 decorated cells in a punctate pattern, but with very specific midzone and midbody localization throughout telophase (Figure 2a). In general, FBXL2 colocalized with Aurora B throughout cytokinesis. Further, FBXL2 expression in cells enhanced levels of the F-box on the midbody, but drastically changed the morphology of the midbody and depleted cytosolic Aurora B within this organelle (Figure 2b). As a complementary approach, FBXL2 knockdown decreased F-box expression coupled with a robust increase in Aurora $B$ protein concentrations on the midbody (Figure 2c). Using MLE cells co-expressing mCherry-tagged histone H2B and MyrPalm-mEGFP as markers for the chromosome and plasma membrane, respectively, we observed that ectopically expressed $F B X L 2$ plasmid induced binucleate cell formation. Specifically, upon FBXL2 plasmid expression, although the furrow ingression was indeed initiated at the end of telophase, it subsequently regressed and resulted in abscission failure and multi-nucleated cells (Figure 2d). Quantitative analysis revealed that $30 \%$ of cells contained two or more nuclei $24 \mathrm{~h}$ after FBXL2 plasmid expression (Figure 2e, right).

FBXL2 depletes Aurora B, causes G2/M arrest and inhibits tumorigenesis. Microscopy results were confirmed by flow cytometry, where cells were first transfected with different amounts of FBXL2 plasmid, labeled with bromodeoxyuridine (5-bromo-2'-deoxyuridine (BrdU) and then collected for processing by a two-color fluorescenceactivated cell sorting (FACS) after $48 \mathrm{~h}$ (Figure 3a). The results indicate a significant increase in a cell population within the G2/M phase (Figure 4a). Ectopic expression of FBXL2 tended to reduce the diploid cell population and increase the numbers of polyploid cells in a dose-dependent manner (Figure 3b). Moreover, ectopic expression of FBXL2 triggered an increase in apoptosis in human lung adenocarcinoma (A549) cells by FACS analysis using Annexin V staining (Figure $3 c$ ). The ability of FBXL2 to induce mitotic abnormalities (Figure $3 b$ ) suggests that it displays tumor suppressor activity. Hence, we first assessed tumorogenicity after implanting A549 cells under stable expression of FBXL2 in athymic nude mice. Stable expression of FBXL2 significantly reduced the tumor size compared with that of the control implants (Figure 3d, upper right panel). Importantly, when tumor tissues were collected from control implants and FBXL2 mice at the end-point and analyzed, immunoblotting showed significant decreases in Aurora B protein levels, coupled with increased levels of FBXL2 protein (Figure $3 e$, lower panel, $n=4$ /group).

SCF-FBXL2 targets Aurora B for polyubiquitination. To confirm the specificity of FBXL2 targeting, we performed coimmunoprecipitation (co-IP) experiments. A549 cells were lysed and subjected to IP using Aurora B antibodies and samples used for F-box protein immunoblotting; out of seven E3 ligase subunits tested, FBXL2 was the only protein detected in the Aurora B immunoprecipitates (Figure 4a). Importantly, inclusion of purified $\mathrm{SCF}^{\mathrm{FBXL} 2}$ with the full 


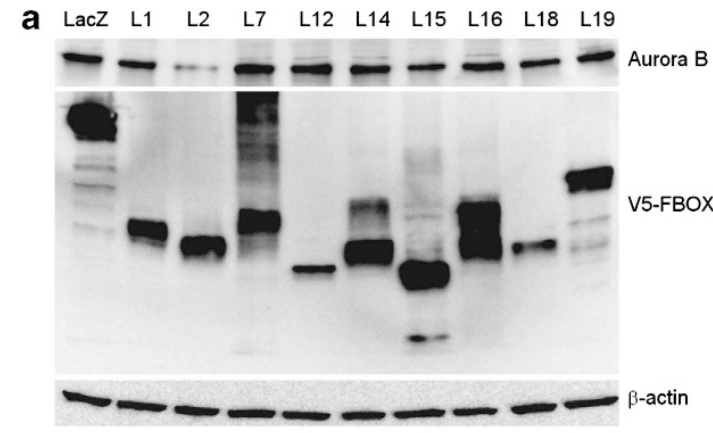

d

b
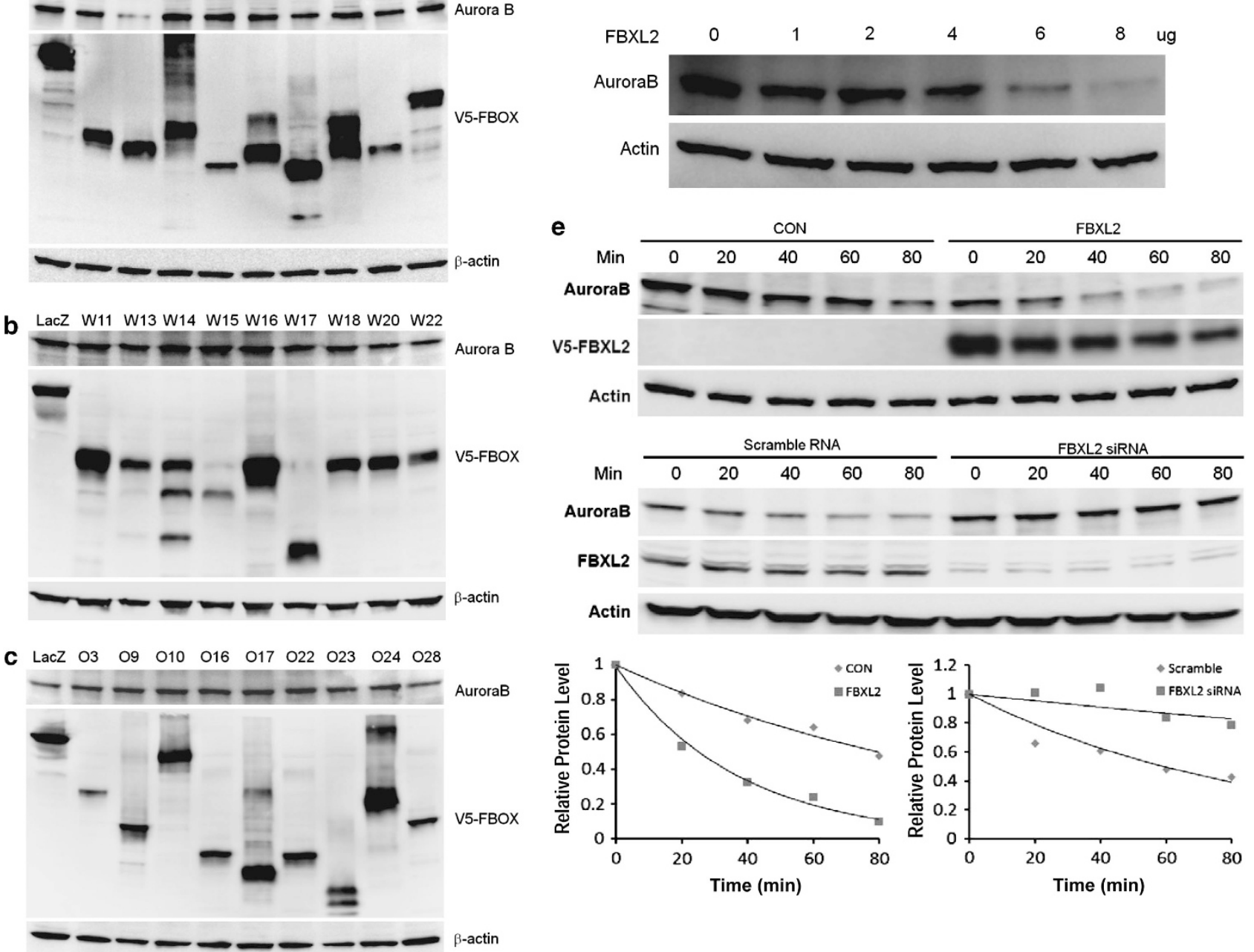

Figure 1 Ectopic expression of FBXL2 specifically induces Aurora B degradation. (a-c) MLE cells $\left(2 \times 10^{5}\right)$ were plated on $35 \mathrm{~mm}$ glass bottom tissue culture dishes for $48 \mathrm{~h}$, cells were then transfected with control plasmid lacZ or other V5-tagged F-box plasmids (4 $\mu \mathrm{g} / \mathrm{dish})$, including $F B X L$ (L) (a), $F B X W(\mathrm{~W})(\mathbf{b})$ and $F B X O(0)(\mathbf{c})$ family members. Cells were collected and cell lysates were analyzed for V5, Aurora B and $\beta$-actin immunoblotting ( $n=2$ experiments). (d) Cells were transfected with increasing amounts of $F B X L 2$ plasmid. Cells were collected and cell lysates were analyzed for V5, Aurora B and $\beta$-actin immunoblotting ( $n=2$ experiments). After $24 \mathrm{~h}$, cell lysates were collected and processed for Aurora B, and $\beta$-actin immunoblotting. (e) Aurora B protein half-life determination after FBXL2 overexpression (upper panel) or a control (CON) plasmid, or FBXL2 knockdown using siRNA (middle lower panel) or a control, scrambled (CON) RNA ( $n=2$ experiments). In overexpression studies, MLE cells were transfected with a plasmid encoding FBXL2 or a Lacz plasmid (4 $\mu \mathrm{g} / \mathrm{dish})$ and $24 \mathrm{~h}$ later cells were collected for V5, Aurora B and $\beta$-actin immunoblotting. For siRNA studies, $1 \times 10^{6} \mathrm{MLE}$ cells were transfected using Lipofectamine 2000 with $10 \mu \mathrm{g}$ of scrambled RNA or Aurora B siRNA and collected after an additional $48 \mathrm{~h}$. Cell lysates were used for V5, Aurora B and $\beta$-actin immunoblotting. Lower graph shows levels of Aurora B quantified densitometrically based on immunoblots

complement of E1 and E2 enzymes, plus ubiquitin, was sufficient to generate polyubiquitinated Aurora B species in vitro (Figure $4 \mathrm{~b}$ ). To determine the ubiquitination acceptor site within Aurora $\mathrm{B}$, we employed both candidate and deletion mapping approaches; Aurora B deletion mutants were first constructed and synthesized in vitro before testing in a ubiquitination assay (Figure 4c). Compared with wild-type (WT) Aurora B and other deletion mutants, a C150 deletion variant and, to a lesser degree, a C200 mutant exhibited resistance to $\mathrm{SCF}^{\mathrm{FBXL2}}$-directed polyubiquitination, suggestive of a potential ubiquitination site or FBXL2-docking motif within the kinase $C$ terminus (Figure 4d). Point mutagenesis of candidate lysine residues within the $\mathrm{NH}_{2}$-terminus indicated that a double mutant, $\mathrm{K}^{102 \mathrm{R}} /{ }^{103 \mathrm{R}}$, and $\mathrm{K}^{207 \mathrm{R}}$ point mutant exhibited partial resistance to
$\mathrm{SCF}^{\mathrm{FBXL2}}$-directed polyubiquitination. Optimal resistance to $\mathrm{SCF}^{\mathrm{FBXL}}$-mediated polyubiquitination was displayed by a triple lysine mutant of Aurora B (K $\left.\mathrm{K}^{102 R} /{ }^{103 R} / 207 \mathrm{R}\right)$ (Figure 4e).

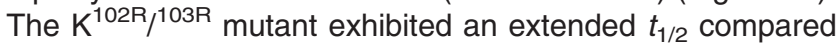
with that of a $\mathrm{K}^{89 \mathrm{R} / 92 \mathrm{R}}$ double mutant, and the $\mathrm{K}^{102 \mathrm{R}} /{ }^{103 \mathrm{R}} / 207 \mathrm{R}$ variant of Aurora $B$ exhibited a significantly extended $t_{1 / 2}$ compared with that of the WT Aurora B (Figure 4f).

Expression of an Aurora B stable mutant induces apoptosis. Next, to evaluate the biological significance of Aurora B mutants, we transfected the plasmids in cells and assessed cytokinesis. Using MLE cells co-expressing mCherry-tagged histone $\mathrm{H} 2 \mathrm{~B}$ and MyrPalm-mEGFP as markers, we observed that the expression of Aurora B triple mutant exhibited significantly delayed anaphase onset 

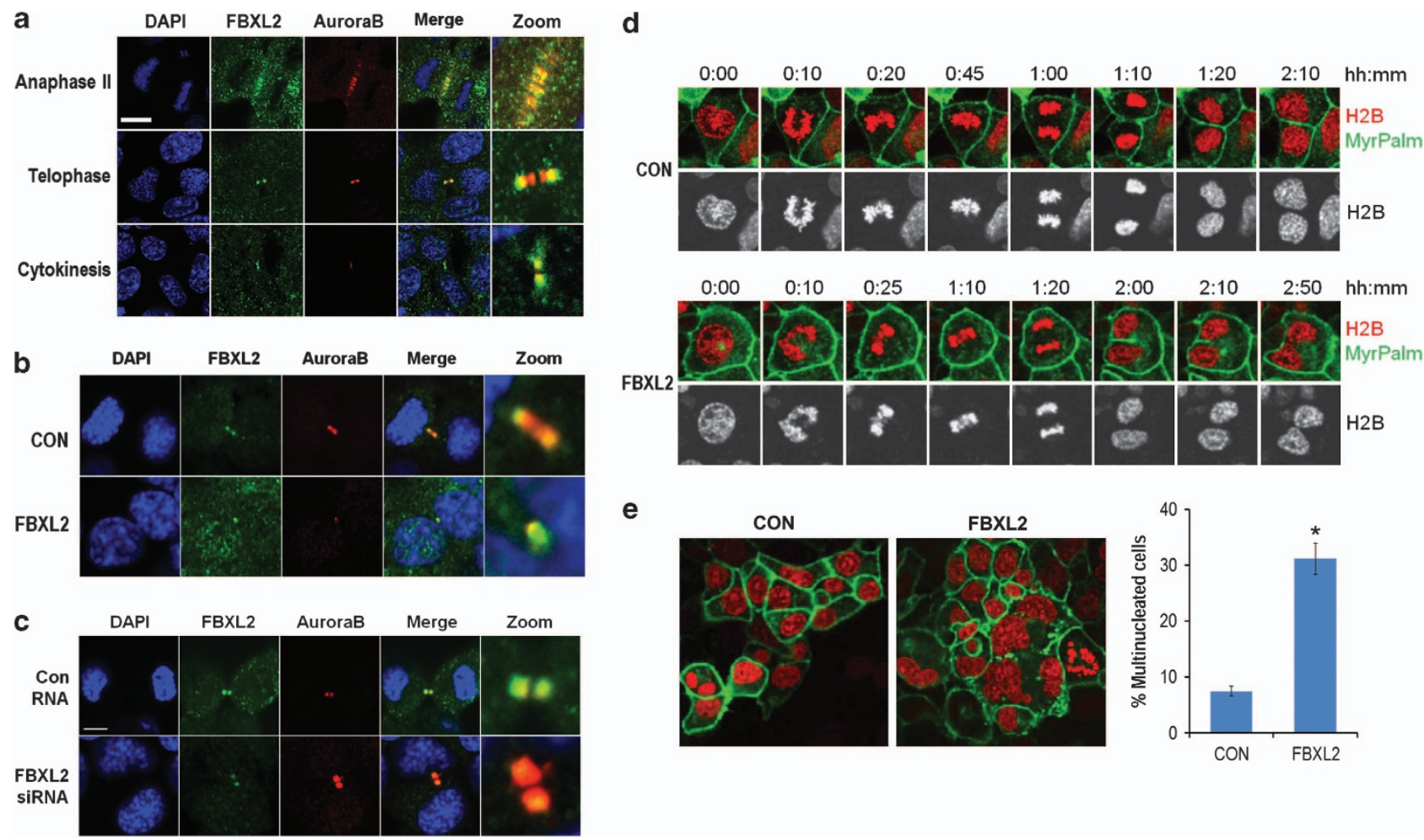

e

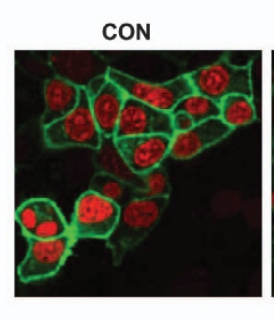

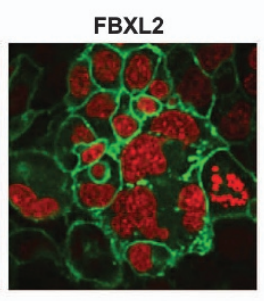

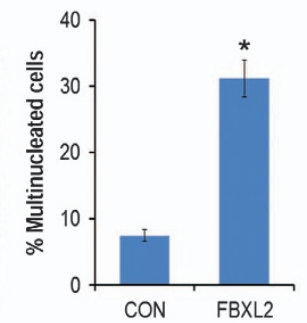

Figure 2 Ectopically expressed FBXL2 depletes Aurora B within the midbody during mitosis and causes tetraploidy. (a) MLE cells $\left(2 \times 10^{5}\right)$ were plated on $35 \mathrm{mM}$ glass bottom tissue culture dishes for $48 \mathrm{~h}$, cells were then washed with PBS and fixed with 4\% paraformaldehyde for $20 \mathrm{~min}$. Cells were co-immunostained for FBXL2 and Aurora B. Nuclei were counterstained using DAPI. Green: FBXL2, red: Aurora B, blue: DAPI. White scale bar indicate $10 \mu \mathrm{m}$. (b) Cells were transfected with either vehicle or FBXL2 plasmid on $35 \mathrm{mM}$ glass bottom tissue culture dishes for $48 \mathrm{~h}$. Cells were then washed with PBS and fixed with $4 \%$ paraformaldehyde for 20 min. Cells were co-immunostained for FBXL2 and Aurora B. Nuclei were counterstained using DAPI. Green: FBXL2, red: Aurora B, blue: DAPI. (c) Cells were transfected with either control or FBXL2 shRNA on $35 \mathrm{~mm}$ glass bottom tissue culture dishes for $48 \mathrm{~h}$. Cells were then washed with PBS and fixed with 4\% paraformaldehyde for 20 min. Cells were co-immunostained for FBXL2 and Aurora B. Nuclei were counterstained using DAPI. Green: FBXL2, red: Aurora B, blue: DAPI. (d) FBXL2 ectopic expression versus a control (CON) plasmid leads to furrow regression (2h) in MLE cells expressing H2B-mCherry and MyrPalm-mEGFP. (e) Multi-nucleate cells in c were quantified and graphed $\left(n=150\right.$ cells, ${ }^{*} P<0.05$ versus control)

(Figure 5a). Specifically, although cells transfected with WT Aurora B underwent chromosome segregation $\sim 40 \mathrm{~min}$ after metaphase onset, the cells transfected with the stable $\mathrm{K}^{102 \mathrm{R} / 103 \mathrm{R} / 207 \mathrm{R}}$ Aurora $\mathrm{B}$ variant exhibited a significant delay of $\sim 40 \mathrm{~min}$ before anaphase onset (Figures $5 b$ and $c$ ). We also observed that the majority of cells $(\sim 80 \%)$ transfected with the stable Aurora B triple mutant with these chromosomal segregation errors underwent apoptosis versus WT cells (Figures $5 c$ and d). As Aurora B is known to localize to the kinetochore, these observations suggest persistent expression of a ubiquitination-resistant Aurora B variant within this organelle during metaphase in cells results in disruption of chromosome separation, thus delayed anaphase and furrow ingression, and subsequent induced apoptosis.

$B C-1258$ induces apoptosis in neoplastic cells by causing mitosis arrest and tetraploidy. FBXL2 is a unique E3 ligase subunit in that it recognizes a calmodulin-binding signature in targets rather than a phosphodegron typical of other F-box proteins. Following its initial description, ${ }^{23}$ FBXL2 was shown to be involved in the ubiquitination of the lipogenic enzyme, cytidylyltransferase (CCT). ${ }^{27,28}$ Our recent studies show that FBXL2 targets important cell cycle proteins, cyclin D3 and cyclin D2, for polyubiquitination and degradation. ${ }^{29}$ We have also shown that FBXL2 regulates the fidelity of cellular division through centrosomal assembly proteins cyclin-dependent kinase 11 (Cdk11), Aurora A and polo-like kinase 4 (Plk4). ${ }^{30}$ Further, FBXL2 is strongly repressed in human lung adenocarcinoma. ${ }^{31}$ Recently, we discovered that FBXL2 itself is subject to polyubiquitination and degradation by another SCF F-box protein, F-box-only protein 3 (FBXO3). ${ }^{32}$ This led us to design, synthesize and test $\mathrm{FBXO} 3$ small molecule inhibitors that might indirectly preserve FBXL2 activity. ${ }^{32}$ Upon examining leukemic peripheral blood mononuclear cell samples, we discovered that FBXL2 protein levels are significantly reduced compared with that of the control, while the substrate of FBXL2, Aurora $\mathrm{B}$, is highly overexpressed in (Figure 6a). To test the hypothesis that Aurora B degradation is sufficient to induce apoptosis and tumor growth, we screened several potential small molecules based on interaction with $\mathrm{FBXO} 3$ that might augment FBXL2 activity. One FBXO3 chemical inhibitor, $\mathrm{BC}-1258$, induced FBXL2 concentrations in a variety of cells (unpublished data, Figure 6b). Although BC-1258 increased FBXL2 protein levels, it decreased FBXL2 substrates, including Aurora B in human leukemia cells (U937 (human leukemic monocyte lymphoma cell line), K562 (human erythroleukemic cell line) and THP1 (human acute monocytic 

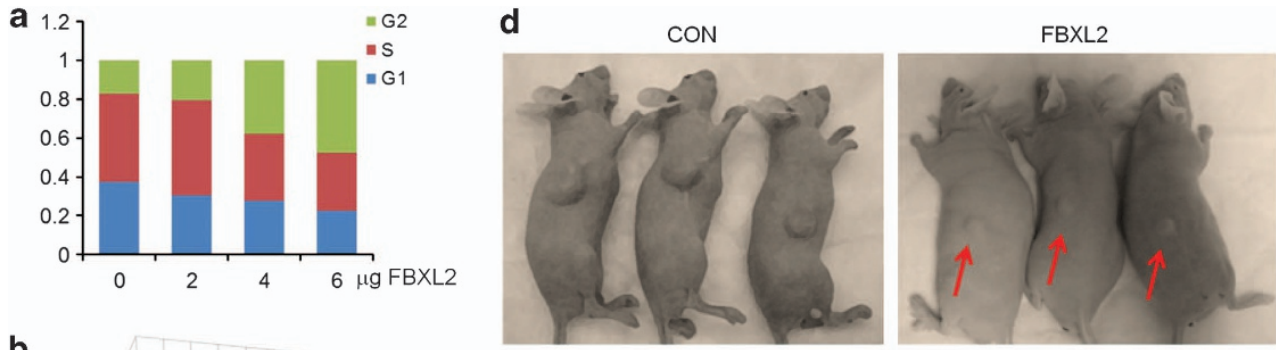

b
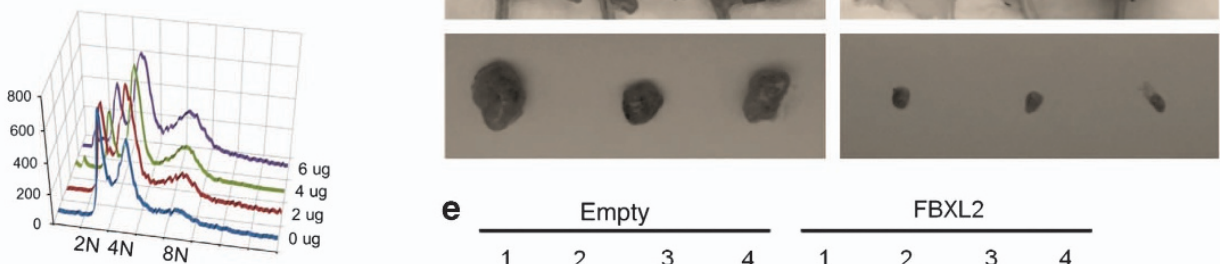

e
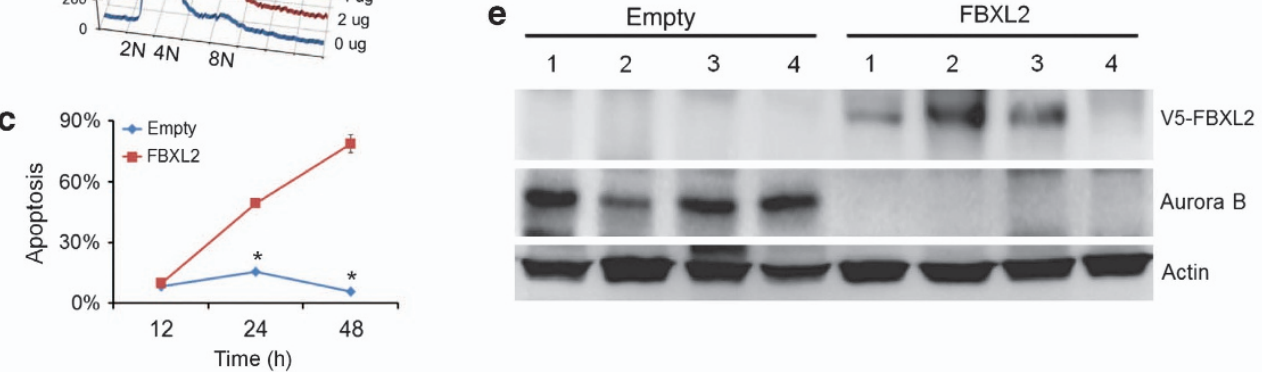

Figure 3 Ectopically expressed FBXL2 depletes Aurora B, causes G2/M arrest and inhibits tumorigenesis. (a-b) MLE cells were transfected with increasing amounts of FBXL2 plasmid, transfected cells were processed by BrdU uptake and 7-AAD staining, followed by FACS cell cycle analysis (a), 2N, 4N and 8N DNA histograms were quantitated and graphed in $\mathbf{b}$ ( $n=2$ experiments). (c) Quantification of FACS analysis showing levels of apoptotic human adenocarcinoma (A549) cells after FBXL2 or control (CON) plasmid overexpression, ( $n=3$ experiments, ${ }^{*} P<0.01$ versus empty). (d) Effect of stable expression of $F B X L 2$ plasmid or a control vector (CON) on growth of $A 549$ tumor implants in nude mice, $n=4$ mice/group. The upper panel showed representative images of variable sizes of xenografts in three nude mice after expression of an empty vector or FBXL2 plasmid (arrows). Lower panel: tumors from four controls and four FBXL2 treated A549 implants in mice were collected at the end point, and assayed for Aurora B and FBXL2 proteins by immunoblotting

leukemia cell line)) (Figures 6c-e). We also tested BC-1258 using flow cytometry, where cells were treated with BC-1258 at different concentrations, labeled with BrdU and then collected for processing bya two-color FACS after $48 \mathrm{~h}$ (Figure 6f). The results indicate a significant increase in a cell population within the G2/M phase (Figure 6f). BC-1258 treatment tended to reduce the diploid cell population and increase the numbers of polyploidal cells in a dose-dependent manner (Figure 6g). Moreover, BC-1258 triggered a significant increase in apoptosis in MLE cells by FACS analysis using Annexin V staining (Figure 6h).

BC-1258 inhibits tumorigenesis. As a complementary in vivo model, we further assessed tumorogenicity after implanting U937 cells in athymic nude mice. Here, in various subsets of mice, animals were treated with three benzathinederived small molecules (BC-1250, BC-1206 and BC-1258) that exhibited variable abilities to induce FBXL2 (unpublished observations). Interestingly, we observed significantly reduced tumor size and weight with $\mathrm{BC}-1258$ treatment compared with that of the vehicle or BC-1250-treated implants (Figures 7a-d). BC-1206 exhibited intermediate ability to suppress tumor growth. Importantly, when tumor tissues were collected from control and treated mice at the endpoint and analyzed, immunoblotting showed significant decreases in Aurora B protein levels with BC-1258 treatment (Figure 7e). To evaluate the toxicity of tested drugs, serum of each mouse was also taken at the end point, and was assayed for creatinine, lactate dehydrogenase, alanine aminotransferase and creatine kinase activity. Here, BC-1258 did not show significant effects in these physiological markers compared with the vehicle (Figures $7 f-i$ ).

\section{Discussion}

Chromosome segregation abnormalities occur frequently in dividing cells, especially during malignant transformation. ${ }^{33,34}$ Usually, defective or delayed chromosome segregation evidenced by lagging or bridged chromosomes will trigger spontaneous furrow regression, resulting in tetraploidization in cells. ${ }^{35}$ Hence, a fundamental issue to be addressed during mitosis is the mechanism(s) in which the majority of cells with chromosome bridges are eventually able to suppress furrow regression and complete faithful mitosis. Aurora $B$ is the key regulator of abscission timing, which responds to chromosome bridge formation by delaying abscission to stabilize the intercellular canal until the chromosome bridge is resolved. ${ }^{36}$ In essence, Aurora B provides a signal for resolution of trapped chromatin to prevent tetraploidy. ${ }^{37}$ Further, cellular concentrations of Aurora $B$ are regulated, in part, by the SCF ${ }^{\text {FBXL2 }}$ machinery. ${ }^{25}$ On the basis of these observations, one fundamental question pursued in this study is by understanding how Aurora $B$ is ubiquitinated at the midbody by FBXL2, can we design, synthesize and test a small molecule that modulates cell growth. Indeed, herein we identified an FBXL2 inducer that was highly effective in 
a

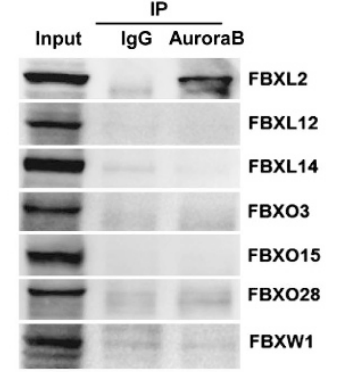

b

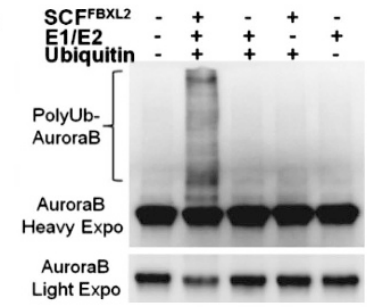

d

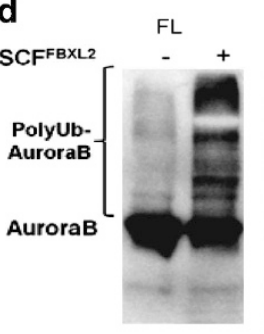

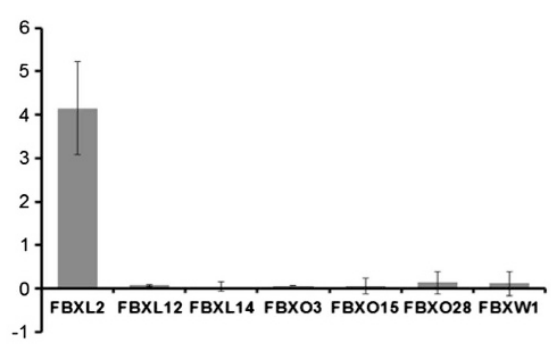

c

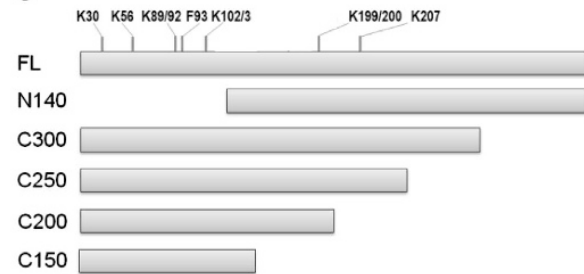

C150 $\square$

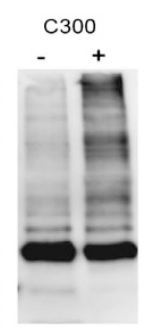

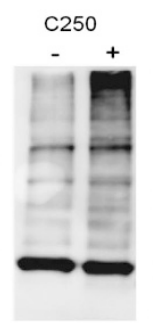

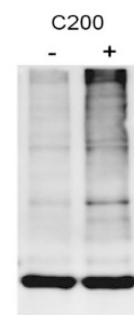

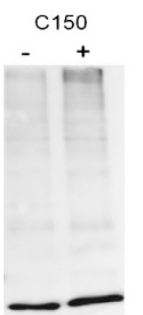

e

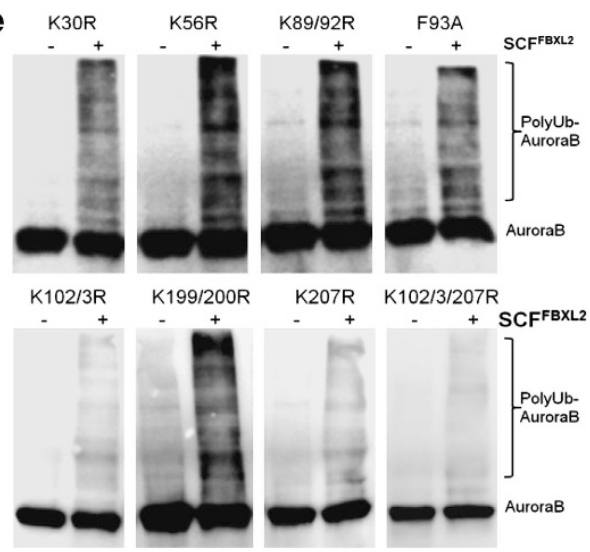

f
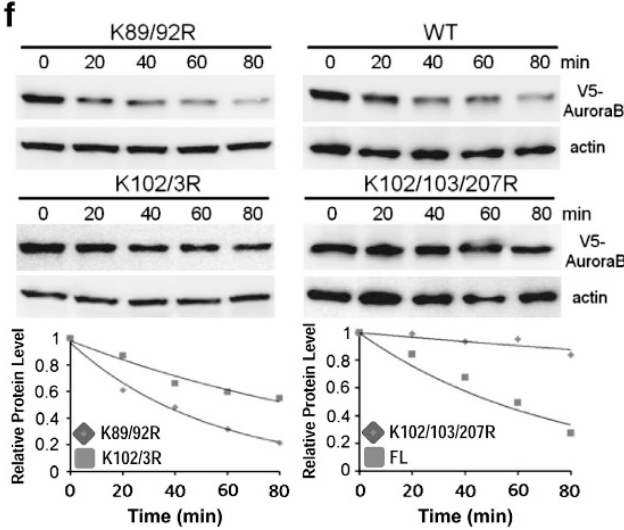

Figure $4 \mathrm{SCF}^{\mathrm{FBXL2}}$ targets Aurora B for polyubiquitination. (a) A549 cells were collected, followed by immunoprecipitation of endogenous Aurora B and then immunoblotting for several E3 ligase subunits. Immunoprecipitated proteins normalized by input were calculated and graphed (right panel). (b) In vitro ubiquitination assays. Purified SCF complexes were incubated with V5-Aurora B and the full complement of ubiquitination reaction components. The reaction products were then used for Aurora B immunoblotting. (c) Diagram of Aurora B deletion mutants constructed. Red lines indicate putative ubiquitin receptor sites or potential residues important for FBXL2 binding. (d) In vitro ubiquitination assays. Purified SCF complexes were incubated with WT V5-Aurora B or various Aurora B deletion mutants and the full complement of ubiquitination reaction components. The reaction products were then used for immunoblotting. (e) In vitro ubiquitination assays. Purified SCF complexes were incubated with Aurora B point mutants and the full complement of ubiquitination reaction components. The reaction products were processed for immunoblotting as above. (f) Aurora B protein half-life determination after the expression of WT V5-Aurora B or point mutants ( $n=2$ experiments). For half-life studies, cells were treated with cycloheximide (40 $\mu \mathrm{g} / \mathrm{ml})$ at different time points after transfection of WT or point-mutant Aurora B plasmids. Cell lysates were collected and processed for Aurora B and $\beta$-actin immunoblotting. Below are decay curves, graphically showing levels of WT or mutant proteins over time after bands were quantitated on immunoblots

reducing both Aurora $B$ levels and tumor viability (Supplementary Figure S2). These observations implicate a role for the F-box protein as a homeostatic sensor that regulates the cytokinesis program through modulation of Aurora B concentrations. This molecular model could be mechanistically significant in providing insight into interventional strategies for carcinogenesis.

When analyzing FBXL2 subcellular localization throughout the cell cycle, FBXL2 specifically localizes within the centrosome during the early phases of mitosis. ${ }^{30}$ After anaphase, FBXL2 relocates at the midzone and midbody during the late phase of mitosis (Figure 2a). In a previous report, Ryser et $a .^{38}$ suggested that the RING finger E3 ligase BRCA1-associated RING domain 1 (BARD1) colocalizes with Aurora B on the midbody, though depletion of WT BARD1 had only minor effects on cell growth. Here, ectopic expression $F B X L 2$ drastically changes the morphology of the midbody and depletes Aurora B protein levels within this organelle, resulting in mitotic arrest, tetraploidization and apoptosis (Figures 2 and 3 ). Thus, the SCF ${ }^{\mathrm{FBXL} 2}$ complex targeting
Aurora B during mitosis might be an integral, constitutive mechanism to tightly balance Aurora B concentrations that regulates replicative capacity under native conditions or during repair after cellular injury.

Although ubiquitin E3 ligase networks target Aurora B, the ubiquitination acceptor sites have not been identified within the kinase. Further, the precise role of the majority of SCF-based E3 ligases in neoplasia have not been established, although repression of FBXL2 in human lung adenocarcinoma ${ }^{31}$ raises the possibility that it might regulate molecular programs involved in mitosis and cell division. In this regard, we showed that FBXL2 is a tumor suppressor, which targets cyclin D3 for polyubiquitination and degradation, and it regulates the fidelity of cellular division through centrosomal assembly proteins Cdk11, Aurora A and Plk4. ${ }^{29,30}$ Indeed, $\mathrm{K}^{207}$ of Aurora $B$ is essential for its SUMOlyation, ${ }^{11}$ and we uncovered three molecular acceptor sites $\left(\mathrm{K}^{102}, \mathrm{~K}^{103}\right.$ and $\left.\mathrm{K}^{207}\right)$ that are potentially important for its ubiquitination. A triple Lys mutant of Aurora B (K $\left.{ }^{102} /{ }^{103} / 207 R\right)$ exhibited optimal resistance to $\mathrm{SCF}^{\mathrm{FBXL2}}$-directed 

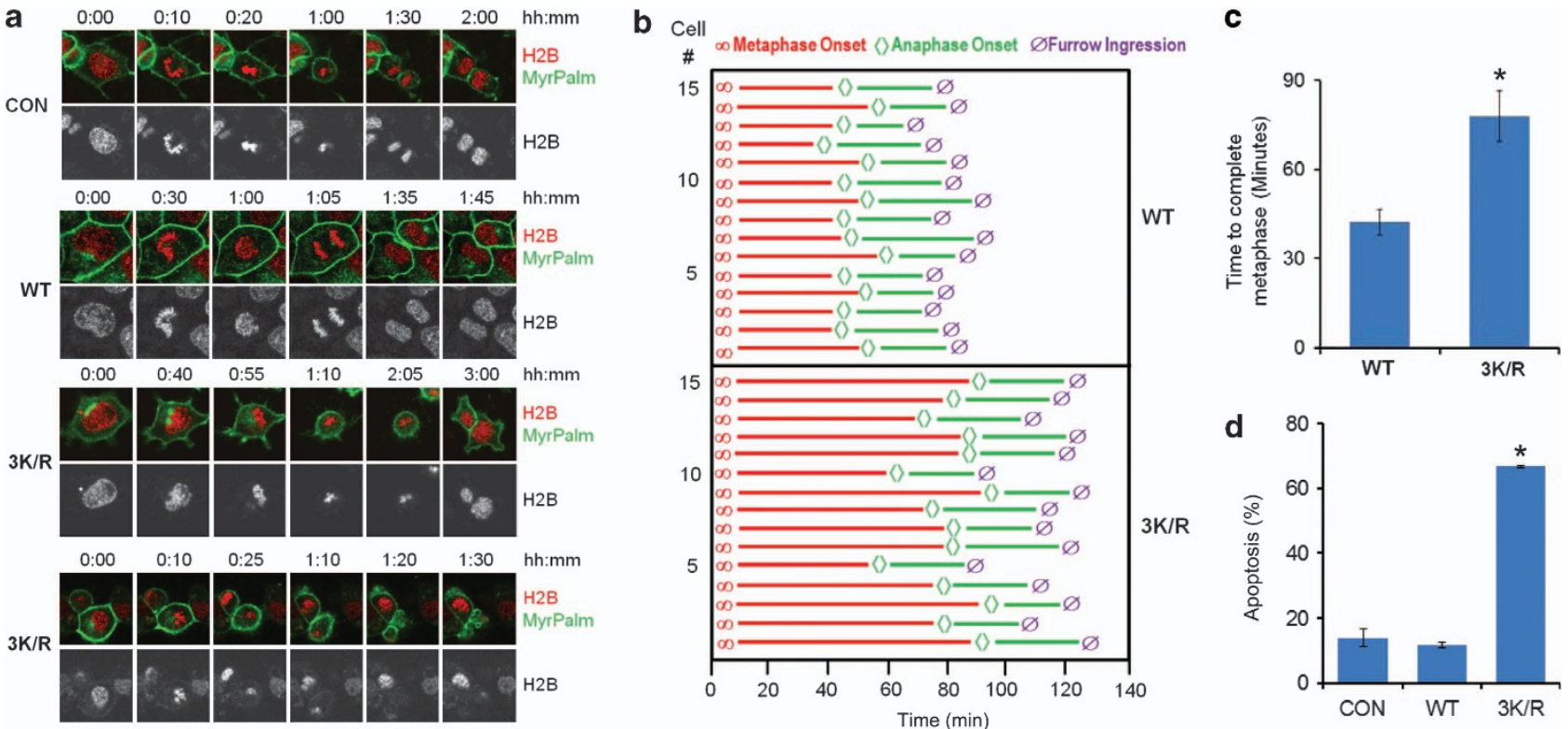

Figure 5 Expression of Aurora B stable mutant-induced apoptosis. (a) MLE cells were transfected with a control empty plasmid and plasmids encoding WT or a triple Aurora B mutant (3K/R) in cells co-expressing mCherry-tagged histone H2B and MyrPalm-mEGFP as markers to assess cytokinesis. Expression of an Aurora B triple K/R mutant led to delays in anaphase onset in cells expressing H2B-mCherry and MyrPalm-mEGFP. (b) Quantitative analysis of mitosis in MLE cells of videos taken in G ( $n=15$ cells in each condition). (c) Quantification of metaphase time in b. (d) Quantification of FACS analysis showing levels of apoptotic cells after WT or Aurora B triple K/R mutant overexpression, ( $n=3$ experiments, ${ }^{*} P<0.01$ versus control)

a

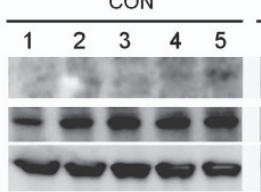

C
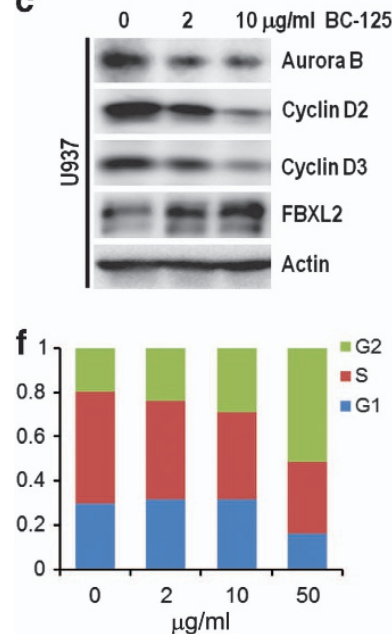

d

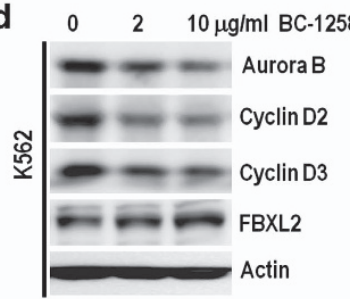

b

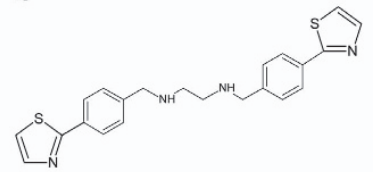

$\begin{array}{llll}\text { e } & 0 & 2 & 10 \mu \mathrm{g} / \mathrm{ml} \mathrm{BC}-1258\end{array}$
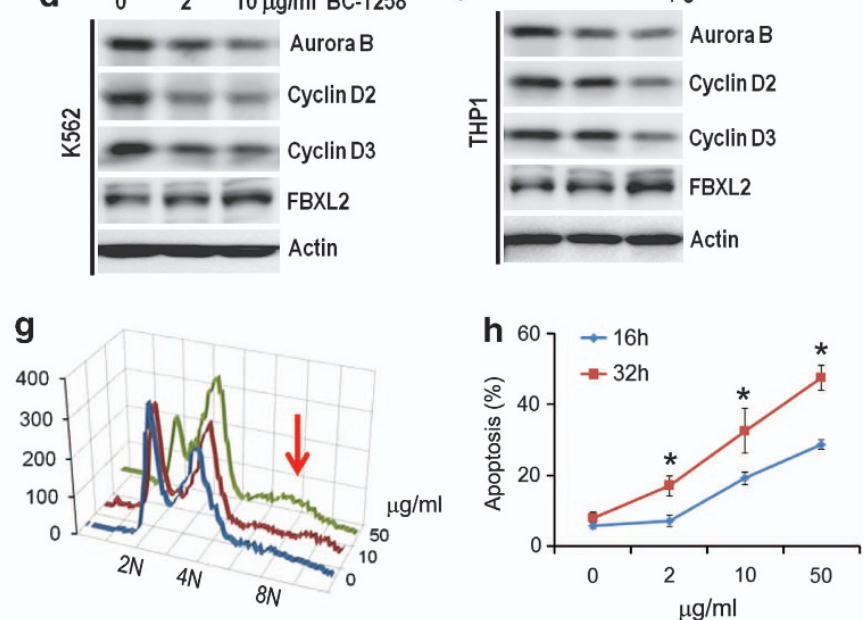

Figure 6 BC-1258 induces apoptosis in leukemic cells by causing mitotic arrest and tetraploidy. (a) Peripheral blood mononuclear cells (PBMCs) from five controls, and AML and ALL subjects were cultured in RPMI medium for $18 \mathrm{~h}$. Cells were then collected, lysed and assayed for FBXL2 and Aurora B by immunoblotting. (b) Structure of BC-1258. (c-e) Human leukemia cells (U937, K562 and THP1 cells) were treated with BC-1258 at different concentrations for $16 \mathrm{~h}$. Cells were collected and assayed for Aurora B, cyclin D2, cyclin D3, $\beta$-actin and FBXL2 immunoblotting. (f-h) MLE cells were treated with BC-1258 at different concentrations for $16 \mathrm{~h}$, cells were processed by BrdU uptake and 7-AAD staining, followed by FACS cell cycle analysis (f), 2N, 4N and 8N DNA histograms were quantitated and graphed in $\mathbf{g}$. (h) Quantification of FACS analysis showing levels of apoptotic MLE cells after BC-1258 treatment at each time point. ${ }^{*} P<0.05$

polyubiquitination (Figure 4), and overexpression of this variant resulted in a significant delay in anaphase onset and apoptosis (Figure 5). Hence, these results further underscore a multi-functional role for Aurora B in mammalian cells. Of note, the Cul3-based E3 ligase KLHL9 and KLHL21 target Aurora B for ubiquitination, remove Aurora B from mitotic 

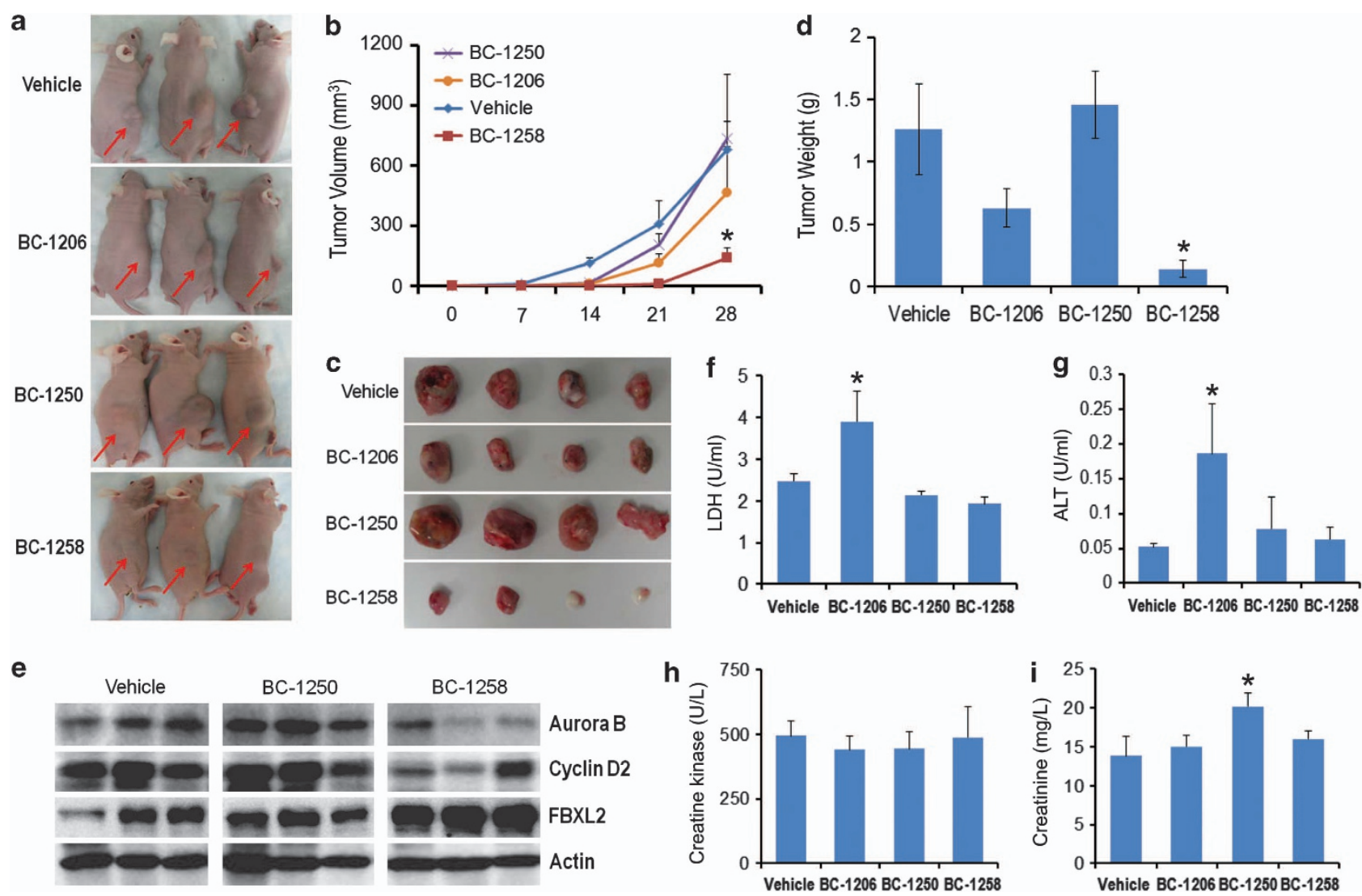

Figure 7 BC-1258 inhibits tumorigenesis. (a-e) Effect of BC-1258 and related FBXL2 inducers on growth of U937 tumor implants in nude mice ( $n=4$ mice/group) with drug concentrations at $30 \mu \mathrm{g} / \mathrm{ml}$ in the drinking water. (a) Representative images of variable sizes of xenograft in three nude mice (arrows) after drug treatment. (b) Tumor volume measurements over time ( $n=4$ mice/group, ${ }^{*} P<0.05$ versus con). (c-d) Tumors were imaged, weighed and graphed $\left(n=4\right.$ mice/group, ${ }^{*} P<0.05$ versus control). (e) Tumors from three controls and three drug-treated U937 implants in mice were collected at the end point, and were assayed for Aurora B, cyclin D2 and FBXL2 proteins by immunoblotting. (f-i) Serum of each mouse were collected at the end point and processed for creatinine, lactate dehydrogenase (LDH), alanine aminotransferase (ALT) and creatine kinase activity

chromosomes and promote anaphase..$^{3,4,14}$ Our findings that overexpressing a ubiquitination-resistant triple Aurora B mutant results in a delay of anaphase onset and mitotic arrest recapitulates the phenotype from KLHL9 E3 ligase depletion. ${ }^{3,14}$

Because of the important role of Aurora B in cytokinesis, and the fact that this kinase is overexpressed in many types of cancer with high proliferative rates and poor prognosis, ${ }^{39}$ the identification of novel molecular targets for developing small molecule Aurora B inhibitors remains an attractive strategy. ${ }^{10,40-42}$ Inhibition of Aurora B kinase causes polyploid cells; however, as these cells have severe chromosomal abnormalities, they eventually stop dividing or undergo apoptosis. One Aurora B inhibitor BI 811283 is currently undergoing phase 2 trials in subjects with advanced solid tumors and acute myeloid leukemia. One advantage of using Aurora B inhibitors as chemotherapeutic agents is their selectivity towards dividing cells. In doing so, this reduces the risk of adverse effects compared with traditional chemotherapeutic modalities. However, it may be more physiologically appealing to identify a small chemical inhibitor that is able to potently reduce Aurora B protein levels rather than just inhibiting its activity to produce a sustained effect. The compound BC-1258 stabilizes FBXL2 to significantly increase its cellular concentrations, which in turn decreases Aurora B protein levels and other FBXL2 substrates, such as cyclin D3, cyclin D2 and CCT. Cyclin D3, cyclin D2 and CCT are highly expressed in cancer tissues and are essential for cell cycle progression. ${ }^{29,30,43}$ Of note, we have recently demonstrated that $\mathrm{BC}-1258$ and related small molecule FBXL2 inducers act by inhibiting the function of another F-box protein, termed FBXO3. ${ }^{32} \mathrm{FBXO} 3$ targets a phosphodegron $\left(\mathrm{Thr}^{404}\right)$ within FBXL2, which is critical for its ability to mediate FBXL2 polyubiquitination and degradation. ${ }^{32}$ Thus, BC-1258 appears to act indirectly by opposing the activity of a FBXL2 repressor. Consistent with this indirect mechanism, by optimizing drug concentrations of BC-1258, we were able to induce apoptosis of tumor cells without producing significant weight loss, systemic toxicity or triggering behavioral abnormalities in mice (Figures $7 \mathrm{f}-\mathrm{i}$ ). Hence, this small chemical entity (BC-1258) may offer a broad range of antitumor activity indirectly targeting many FBXL2 substrates implicated in tumorogenesis; additional studies in larger tumorogenic models and assessment of off-target effects are needed to fully ascertain its therapeutic potential. 


\section{Materials and Methods}

Materials. The sources of the transformed MLE cell line and antibodies were described previously. ${ }^{44,45}$ Purified SCF ${ }^{\mathrm{FBX} 2}$ was purchased from Abnova (Walnut, CA, USA). Purified ubiquitin, E1, E2 and cycloheximide were purchased from Calbiochem (La Jolla, CA, USA). Aurora B rabbit polyclonal antibody, $\gamma$-tubulin and $\alpha$-tubulin antibodies were purchased from Cell Signaling (Danvers, MA, USA) and Abcam (Cambridge, MA, USA). Cobalt affinity beads were purchased from Clontech (Mountain view, CA, USA). Lipofectamine 2000, mouse monoclonal V5 antibody, fluorescent labeled antibodies, the pcDNA3.1D cloning kit, E. coli One Shot competent cells, the pENTR Directional TOPO cloning kits and the Gateway mammalian expression system were from Invitrogen (Carlsbad, CA, USA). FACS kits were purchased from BD Biosciences (San Jose, CA, USA). The F-box proteins cDNA were purchased from OpenBiosystems (Huntsville, AL, USA). Nucleofector transfection kits were from Amaxa (Gaithersbury, MD, USA). Immobilized protein A/G beads were from Pierce (Rockford, IL, USA). Annexin V staining kits and the complete proteasome inhibitors were from Roche (Madison, WI, USA). Goat polyclonal FBXL2 antibody, scrambled RNA and siRNAs were from Santa Cruz Biotechnology (Santa Cruz, CA, USA). Rabbit polyclonal FBXL2 antibody was from AvivaBioscience (San Diego, CA, USA). All DNA sequencing was performed by the University of Pittsburgh DNA Core Facility.

Cell culture. MLE cells were cultured in Dulbecco's modified Eagle medium-F12 (Gibco, Grand Island, NY, USA) supplemented with 2-10\% fetal bovine serum. A549 cells were cultured in F12/K medium (Gibco) supplemented with $10 \%$ fetal bovine serum. THP1, MOLM (egakaryoblastic leukemia cell line), K562 and U937 cells were cultured in RPMI 1640 with 10\% fetal bovine serum. For half-life studies, cells were treated with cycloheximide $(40 \mu \mathrm{g} / \mathrm{ml})$ at different time points in blank medium. Cells lysates were prepared by brief sonication in $150 \mathrm{mM}$ $\mathrm{NaCl}, 50 \mathrm{mM}$ Tris, $1.0 \mathrm{mM}$ EDTA, $2 \mathrm{mM}$ dithiothreitol, $0.025 \%$ sodium azide and $1 \mathrm{mM}$ phenylmethylsulfonyl fluoride (Buffer A) at $4^{\circ} \mathrm{C}$.

Expression of recombinant protein and RNAi. All plasmids were delivered into cells using nucleofection or Lipofectamine $20000^{46,47}$ Cellular expression of green fluorescent-tagged plasmids using this device was achieved at $>90 \%$. For siRNA studies, $1 \times 10^{6}$ cells were transfected using Lipofectamine 2000 with $10 \mu \mathrm{g}$ of RNA and were collected after an additional $48 \mathrm{~h}$.

Co-IP and binding assays. Two hundred and fifty micrograms of total protein from cell lysates was precleared with $20 \mu$ l of protein $A / G$ beads for $1 \mathrm{~h}$ at $4{ }^{\circ} \mathrm{C}$. Five micrograms of primary antibody was added for $18 \mathrm{~h}$ of incubation at $4{ }^{\circ} \mathrm{C}$. Foty microliters of protein $\mathrm{A} / \mathrm{G}$ beads were added for an additional $6 \mathrm{~h}$ of incubation. Beads were slowly centrifuged and washed five times using $50 \mathrm{mM}$ HEPES, $150 \mathrm{mM} \mathrm{NaCl}, 0.5 \mathrm{mM}$ EGTA, $50 \mathrm{mM} \mathrm{NaF}, 10 \mathrm{mM} \mathrm{Na}_{3} \mathrm{VO}_{4}, 1 \mathrm{mM}$ phenylmethylsulfonyl fluoride, $20 \mu \mathrm{M}$ leupeptin and $1 \%$ (v/v) Triton X-100 (RIPA) buffer, as described. ${ }^{48}$ The beads were heated at $100^{\circ} \mathrm{C}$ for 5 min with $80 \mu \mathrm{l}$ of protein sample buffer before SDS-PAGE and immunoblotting.

Microscopy and immunostaining. All the microscopy work was done on a Nikon (Nikon Instruments, Melville, NY, USA) A1 confocal microscope using a $\times 60$ oil objective. The microscope was equipped with Ti Perfect Focus system and Tokai Hit live cell chamber (Nikon Instruments) providing a humidified atmosphere at $37^{\circ} \mathrm{C}$ with $5 \% \mathrm{CO}$. For long-term movie acquisition, sample illumination was kept to minimum to reduce the effect of photobleaching. Transfected cells $\left(2 \times 10^{5}\right)$ were plated at $70 \%$ confluence on $35 \mathrm{~mm}$ MatTek glass bottom culture dishes. Immunofluorescent cell imaging was performed on a Nikon A1 confocal microscope using $405,458,488,514$ or $647 \mathrm{~nm}$ wavelengths. All experiments were done with a $60 \times$ oil differential interference contrast objective lens. Cells were washed with PBS and fixed with $4 \%$ paraformaldehyde for $20 \mathrm{~min}$, then exposed to $2 \% \mathrm{BSA}, 1: 500$ primary antibodies, and 1:1000 Alexa 488-, Alexa 567- or Alexa 647-labeled chicken anti-mouse, donkey anti-goat or goat anti-rabbit secondary antibody sequentially for immunostaining. Image analysis was by Nikon NIS-element (Nikon Instruments) and ImageJ software (National Institutes of Health, Bethesda, MD, USA).

In vitro ubiquitin conjugation assays. The ubiquitination of V5-Aurora B was performed in a volume of $25 \mu$ l containing $50 \mathrm{mM}$ Tris $\mathrm{pH} 7.6,5 \mathrm{mM} \mathrm{MgCl}_{2}$, $0.6 \mathrm{mM}$ DTT, $2 \mathrm{mM}$ ATP, $1.5 \mathrm{ng} / \mu \mathrm{l} \mathrm{E} 1,10 \mathrm{ng} / \mu \mathrm{l} \mathrm{Ubc5}, 10 \mathrm{ng} / \mu \mathrm{l} \mathrm{Ubc7,} 1 \mu \mathrm{g} / \mu \mathrm{l}$ ubiquitin (Calbiochem), $1 \mu \mathrm{M}$ ubiquitin aldehyde, 4-16 $\mu$ l of purified Cullin1, Skp1, $\mathrm{Rbx} 1$ and in vitro synthesized FBXL2. Reaction products were processed for V5 immunoblotting.
Quantitative RT-PCR, cloning and mutagenesis. Total RNA was isolated and reverse transcription was performed followed by quantitative real-time PCR with SYBR Green qPCR mixture as described. ${ }^{49}$ PCR-based approaches were used to clone different F-box proteins into pcDNA3.1D/v5-his (Invitrogen) for constitutive expression in cells. All mutant constructs were generated using PCR-based approaches using appropriate primers or site-directed mutagenesis.

Cell cycle and apoptosis analysis. Transfected cells were incubated with $\operatorname{BrdU}(20 \mu \mathrm{M})$ for $40 \mathrm{~min}$, fixed and stained following the manufacturer's protocols (BD Biosciences, Sparks, MD, USA). FACS samples were analyzed with the AccuriC6 system. DNA content was analyzed using FCS3 express software (De Novo Software, Los Angeles, CA, USA). When analyzing the cell cycle, a gate for 7AAD was set to exclude polyploidy cells. Otherwise, cells were counted and the percentage of cells with $2 \mathrm{~N}, 4 \mathrm{~N}$ and $8 \mathrm{~N}$ DNA content was expressed as a percentage of total cells. Cells were also stained with Annexin $V$ for $15 \mathrm{~min}$ following the manufacturer's protocol (Roche). Apoptotic cells were counted, and apoptotic cells were expressed as a percentage of total cells.

Animal studies. Nude/Nude mice (purchased from Charles River, Wilmington, MA, USA) were acclimated at the University of Pittsburgh Animal Care Facility and were maintained according to all federal guidelines and under the University of Pittsburgh Institutional Animal Care and Use Committee approved protocols. Mice were deeply anesthetized with ketamine $(80-100 \mathrm{mg} / \mathrm{kg}$ intraperitoneally (i.p.) and xylazine (10 mg/kg i.p.), followed by i.p. injection of $5 \times 10^{6}$ A549 cells $(100 \mu \mathrm{l})$ into the right shoulder. For BC-1258 treatment, an aliquot of bc- 1258 stock solution $(5 \mathrm{mg} / \mathrm{ml})$ was added to drinking water (containing $2 \%$ sucrose) to maintain the final drug concentration at $30 \mu \mathrm{g} / \mathrm{ml}$. Mice were closely monitored every week; tumor volume was calculated using a formula length $\times$ width $\times$ height $\times \pi / 6$.

Statistical analysis. Statistical comparisons were performed with the Prism program, version 4.03 (GraphPad Software, Inc., San Diego, CA, USA) using an ANOVA 1 or an unpaired 2 Student's $t$-test with $P<0.05$ indicative of significance.

\section{Conflict of Interest}

A provisional patent application (US 61/657, 423) covering FBXL2 activators was filed jointly through the United States Department of Veterans Affairs and the University of Pittsburgh.

Acknowledgements. We thank DW Gerlich for providing pH2B-mCherryIRES-puro2 and pMyrPalm-mEGFP plasmids. This material is based upon work supported, in part, by the US Department of Veterans Affairs, Veterans Health Administration, Office of Research and Development, and Biomedical Laboratory Research and Development. This work was supported by a Merit Review Award from the US Department of Veterans Affairs and National Institutes of Health R01 grants HL116472 (to BBC), HL096376, HL097376 and HL098174 (to RKM).

\section{Author Contributions}

BBC was responsible for oversight of the studies, designed the study, performed experiments, analyzed the data and wrote the manuscript; TAC and JRG performed experiments and assisted with animal experiments. RKM revised the manuscript and assisted BBC with direction of the study.

1. Bischoff JR, Anderson L, Zhu Y, Mossie K, Ng L, Souza B et al. A homologue of Drosophila aurora kinase is oncogenic and amplified in human colorectal cancers. EMBO J 1998; 17: 3052-3065.

2. Giet R, Prigent C. Aurora/lpl1p-related kinases, a new oncogenic family of mitotic serine-threonine kinases. J Cell Sci 1999; 112(Pt 21): 3591-3601.

3. Sumara I, Quadroni M, Frei C, Olma MH, Sumara G, Ricci R et al. A Cul3-based E3 ligase removes Aurora $B$ from mitotic chromosomes, regulating mitotic progression and completion of cytokinesis in human cells. Dev Cell 2007; 12: 887-900.

4. Sumara I, Peter M. A Cul3-based E3 ligase regulates mitosis and is required to maintain the spindle assembly checkpoint in human cells. Cell Cycle 2007; 6: 3004-3010.

5. Monje-Casas F, Prabhu VR, Lee BH, Boselli M, Amon A. Kinetochore orientation during meiosis is controlled by Aurora B and the monopolin complex. Cell 2007; 128: 477-490.

6. Adams RR, Maiato H, Earnshaw WC, Carmena M. Essential roles of Drosophila inner centromere protein (INCENP) and aurora B in histone $\mathrm{H} 3$ phosphorylation, metaphase 
chromosome alignment, kinetochore disjunction, and chromosome segregation. J Cell Biol 2001; 153: 865-880.

7. Giet R, Glover DM. Drosophila aurora B kinase is required for histone $\mathrm{H} 3$ phosphorylation and condensin recruitment during chromosome condensation and to organize the central spindle during cytokinesis. J Cell Biol 2001; 152: 669-682.

8. Terada Y, Tatsuka M, Suzuki F, Yasuda Y, Fujita S, Otsu M. AIM-1: a mammalian midbody-associated protein required for cytokinesis. EMBO J 1998; 17: 667-676.

9. Hauf S, Cole RW, LaTerra S, Zimmer C, Schnapp G, Walter R et al. The small molecule Hesperadin reveals a role for Aurora $B$ in correcting kinetochore-microtubule attachment and in maintaining the spindle assembly checkpoint. J Cell Biol 2003; 161: 281-294.

10. Soncini $C$, Carpinelli $P$, Gianellini L, Fancelli D, Vianello $P$, Rusconi $L$ et al. PHA-680632, a novel Aurora kinase inhibitor with potent antitumoral activity. Clin Cancer Res 2006; 12: $4080-4089$.

11. Fernandez-Miranda G, Perez de Castro I, Carmena M, Aguirre-Portoles C, Ruchaud S, Fant X et al. SUMOylation modulates the function of Aurora-B kinase. J Cell Sci 2010; 123: 2823-2833.

12. Littlepage LE, Ruderman JV. Identification of a new APC/C recognition domain, the A box which is required for the Cdh1-dependent destruction of the kinase Aurora-A during mitotic exit. Genes Dev 2002; 16: 2274-2285

13. Nguyen HG, Chinnappan D, Urano T, Ravid K. Mechanism of Aurora-B degradation and its dependency on intact KEN and A-boxes: identification of an aneuploidy-promoting property. Mol Cell Biol 2005; 25: 4977-4992.

14. Maerki S, Olma MH, Staubli T, Steigemann P, Gerlich DW, Quadroni M et al. The Cul3-KLHL21 E3 ubiquitin ligase targets aurora B to midzone microtubules in anaphase and is required for cytokinesis. J Cell Biol 2009; 187: 791-800.

15. Tyers M, Willems AR. One ring to rule a superfamily of E3 ubiquitin ligases. Science 1999; 284: 3-4.

16. Guardavaccaro D, Frescas D, Dorrello NV, Peschiaroli A, Multani AS, Cardozo T et al. Control of chromosome stability by the beta-TrCP-REST-Mad2 axis. Nature 2008; 452 : 365-369.

17. Seki A, Coppinger JA, Du H, Jang CY, Yates JR 3rd, Fang G. Plk1- and beta-TrCPdependent degradation of Bora controls mitotic progression. J Cell Biol 2008; 181: 65-78.

18. Gusti A, Baumberger N, Nowack M, Pusch S, Eisler H, Potuschak T et al. The Arabidopsis thaliana F-box protein $\mathrm{FBL} 17$ is essential for progression through the second mitosis during pollen development. PLoS One 2009; 4: e4780.

19. D'Angiolella V, Donato V, Vijayakumar S, Saraf A, Florens L, Washburn MP et al. SCF(Cyclin F) controls centrosome homeostasis and mitotic fidelity through CP110 degradation. Nature 2010; 466: 138-142.

20. Zheng N, Schulman BA, Song L, Miller JJ, Jeffrey PD, Wang $P$ et al. Structure of the Cul1-Rbx1-Skp1-F boxSkp2 SCF ubiquitin ligase complex. Nature 2002; 416: 703-709.

21. Cardozo T, Pagano M. The SCF ubiquitin ligase: insights into a molecular machine. Nat Rev Mol Cell Biol 2004; 5: 739-751.

22. Cenciarelli C, Chiaur DS, Guardavaccaro D, Parks W, Vidal M, Pagano M. Identification of a family of human F-box proteins. Curr Biol 1999; 9: 1177-1179.

23. Ilyin GP, Rialland M, Glaise D, Guguen-Guillouzo C. Identification of a novel Skp2-like mammalian protein containing F-box and leucine-rich repeats. FEBS Lett 1999; 459: 75-79.

24. Liu D, Zhang N, Du J, Cai X, Zhu M, Jin C et al. Interaction of Skp1 with CENP-E at the midbody is essential for cytokinesis. Biochem Biophys Res Commun 2006; 345: 394-402.

25. Mallampalli RK, Glasser JR, Coon TA, Chen BB. Calmodulin protects Aurora B on the midbody to regulate the fidelity of cytokinesis. Cell Cycle 2013; 12: 663-673.

26. Coon TA, Glasser JR, Mallampalli RK, Chen BB. Novel E3 ligase component FBXL7 ubiquitinates and degrades Aurora A, causing mitotic arrest. Cell Cycle 2012; 11: 721-729.

27. Wang C, Gale M Jr., Keller BC, Huang H, Brown MS, Goldstein JL et al. Identification of FBL2 as a geranylgeranylated cellular protein required for hepatitis $C$ virus RNA replication. $\mathrm{Mol}$ Cell 2005; 18: 425-434.

28. Chen BB, Coon TA, Glasser JR, Mallampalli RK. Calmodulin antagonizes a calcium-activated SCF ubiquitin E3 ligase subunit, FBXL2, to regulate surfactant homeostasis. Mol Cell Biol 2011; 22: 22.

29. Chen BB, Glasser JR, Coon TA, Mallampalli RK. F-box protein FBXL2 exerts human lung tumor suppressor-like activity by ubiquitin-mediated degradation of cyclin D3 resulting in cell cycle arrest. Oncogene 2011; 31: 2566-2579.
30. Chen BB, Glasser JR, Coon TA, Mallampalli RK. FBXL2 is a ubiquitin E3 ligase subunit that triggers mitotic arrest. Cell Cycle 2011; 10: 3487-3494.

31. Malard V, Berenguer F, Prat O, Ruat S, Steinmetz G, Quemeneur E. Global gene expression profiling in human lung cells exposed to cobalt. BMC Genomics 2007; 8: 147.

32. Chen BB, Coon TA, Glasser JR, McVerry BJ, Zhao J, Zhao Y et al. A combinatorial F box protein directed pathway controls TRAF stability to regulate inflammation. Nat Immunol 2013; 14: 470-479.

33. Cimini $D$, Mattiuzzo M, Torosantucci L, Degrassi F. Histone hyperacetylation in mitosis prevents sister chromatid separation and produces chromosome segregation defects. $\mathrm{Mol}$ Biol Cell 2003; 14: 3821-3833.

34. Cimini D, Moree B, Canman JC, Salmon ED. Merotelic kinetochore orientation occurs frequently during early mitosis in mammalian tissue cells and error correction is achieved by two different mechanisms. J Cell Sci 2003; 116: 4213-4225.

35. Weaver BA, Silk AD, Cleveland DW. Cell biology: nondisjunction, aneuploidy and tetraploidy. Nature 2006; 442: E9-10; discussion E.

36. Steigemann P, Wurzenberger C, Schmitz MH, Held M, Guizetti J, Maar S et al. Aurora B-mediated abscission checkpoint protects against tetraploidization. Cell 2009; 136: 473-484.

37. Chen CT, Doxsey S. A last-minute rescue of trapped chromatin. Cell 2009; 136: 397-399.

38. Ryser S, Dizin E, Jefford CE, Delaval B, Gagos S, Christodoulidou A et al. Distinct roles of BARD1 isoforms in mitosis: full-length BARD1 mediates Aurora $B$ degradation, cancerassociated BARD1beta scaffolds Aurora B and BRCA2. Cancer Res 2009; 69: 1125-1134.

39. Green MR, Woolery JE, Mahadevan D. Update on Aurora kinase targeted therapeutics in oncology. Expert Opin Drug Discov 2011; 6: 291-307.

40. Harrington EA, Bebbington D, Moore J, Rasmussen RK, Ajose-Adeogun AO, Nakayama T et al. VX-680, a potent and selective small-molecule inhibitor of the Aurora kinases, suppresses tumor growth in vivo. Nat Med 2004; 10: 262-267.

41. Gadea BB, Ruderman JV. Aurora kinase inhibitor ZM447439 blocks chromosome-induced spindle assembly, the completion of chromosome condensation, and the establishment of the spindle integrity checkpoint in Xenopus egg extracts. Mol Biol Cell 2005; 16 : 1305-1318.

42. Hardwicke MA, Oleykowski CA, Plant R, Wang J, Liao Q, Moss K et al. GSK1070916, a potent Aurora $\mathrm{B} / \mathrm{C}$ kinase inhibitor with broad antitumor activity in tissue culture cells and human tumor xenograft models. Mol Cancer Ther 2009; 8: 1808-1817.

43. Chen BB, Glasser JR, Coon TA, Zou C, Miller HL, Fenton M et al. F-box protein FBXL2 targets cyclin D2 for ubiquitination and degradation to inhibit leukemic cell proliferation. Blood 2012; 119: 3132-3141.

44. Ray NB, Durairaj L, Chen BB, McVerry BJ, Ryan AJ, Donahoe M et al. Dynamic regulation of cardiolipin by the lipid pump Atp8b1 determines the severity of lung injury in experimental pneumonia. Nat Med 2010; 16: 1120-1127.

45. Chen BB, Mallampalli RK. Calmodulin binds and stabilizes the regulatory enzyme, CTP: phosphocholine cytidylyltransferase. J Biol Chem 2007; 282: 33494-33506.

46. Agassandian M, Chen BB, Schuster CC, Houtman JC, Mallampalli RK. 14-3-3zeta escorts CCTalpha for calcium-activated nuclear import in lung epithelia. FASEB J 2010; 24 : 1271-1283.

47. Chen BB, Mallampalli RK. Masking of a nuclear signal motif by monoubiquitination leads to mislocalization and degradation of the regulatory enzyme cytidylyltransferase. Mol Cell Biol 2009; 29: 3062-3075.

48. Mallampalli RK, Ryan AJ. Salome RG, Jackowski S. Tumor necrosis factor-alpha inhibits expression of CTP: phosphocholine cytidylyltransferase. J Biol Chem 2000; 275: 9699-9708.

49. Butler PL, Mallampalli RK. Cross-talk between remodeling and de novo pathways maintains phospholipid balance through ubiquitination. J Biol Chem 2010; 285: $6246-6258$.

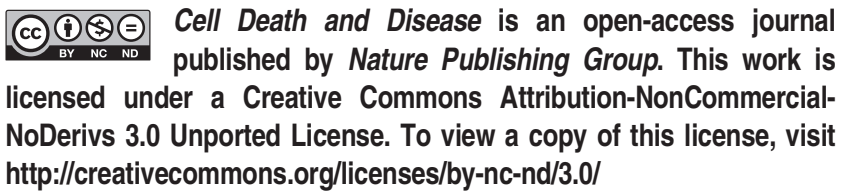
http://creativecommons.org/licenses/by-nc-nd/3.0/

Supplementary Information accompanies this paper on Cell Death and Disease website (http://www.nature.com/cddis) 